\title{
Visual hallucinations with written words in a case of left parietotemporal lesion
}

\author{
Marc Rousseaux, Dominique Debrock, Maryline Cabaret, Marc Steinling
}

\begin{abstract}
A 15 year old ambidextrous patient presented with left temporoparietal lesions after head trauma. Seizures associated with visual hallucinations of written words arose six months later. Electroencephalography showed spike and wave complexes with phase opposition over the left parietal area. On MRI a post-traumatic porencephalic lesion was seen in area 7 and the superior part of area 39 of Brodmann; on $T 2$ sequences, it was surrounded by a hyperecho predominating in the inferior part of the parietal lobe and extending in the posteroexternal temporal cortex. This first description of hallucinations of written words raises the possibility of the presence, in the temporoparietal cortex, of specific representations ("lexicon") of corresponding information.
\end{abstract}

$(\mp$ Neurol Neurosurg Psychiatry 1994;57:1268-1271)

Visual hallucinations have been described in epileptic seizures and during electrical stimulation of the occipital, ${ }^{1-6}$ temporal, and parietal cortices. ${ }^{7}$ Occipital activation most commonly results in elementary visual perceptions, sensation of light and colours, simple geometric figures, and movements. Posterior temporal activation primary or secondary to occipital excitation results in more complex visual hallucinations consisting of faces, scenes that may include people, pictures, and objects. ${ }^{68}$ It is generally considered that these manifestations are related to the functional role of the associated cortex, and particularly the progressive integration of the complex visual percepts, leading to recognition or identification of objects, faces, or scenes. ${ }^{9}$

Adjoining cortical structures are also concerned with the treatment of written language; this point is suggested by the description of "pure alexias"10 in patients with internal occipital lesions and "alexia with agraphia" 11 in patients with posterior parietal lesions. No ictal manifestation related to written language, however, has apparently been described in the literature.

In this paper we report the case of a left parietotemporal post-traumatic lesion, lead- ing to epileptic seizures associated with complex visual hallucinations and perception of written words.

\section{Case report}

A 15 year old French ambidextrous boy $\left(12 / 24\right.$ on the Oldfield ${ }^{12}$ scale) who was a top grade student, had a head injury on 9 June 1987. He initially presented with reactive coma (Glasgow coma scale 10) and mild right sided motor deficit. Computed tomography showed left parietal haemorrhage. After the disappearance of the coma state, examination on the 10th day showed a severe communication disorder concerning verbal and written messages.

On entering the rehabilitation centre, 20 days later, the patient showed severe intellectual slowness. He was virtually mute and hardly executed simple orders. He was also severely apractic in daily life. Light motor and sensory deficits were seen; they disappeared in a few months. His visual field was clinically normal.

Language and cognitive rehabilitation were actively followed during six months in hospital. Recovery was rapid but there were severe difficulties in word finding and paraphasias (verbal and phonemic), without anarthria. The language therapist noted important facilitation of oral and written evocation of words when the patient had just called to mind the written image of these words (verbal naming of images: two of 22 with three semantic and four phonemic paraphasias; no facilitation by giving the first phoneme; 10 of 22 with facilitation by the evocation of the written image of the word). This strategy was then systematically used in rehabilitation, firstly in naming and then in spontaneous speech. The patient acquired the habit of using it in daily life. When discharged (January 1988), discrete word finding difficulties, rare morphological or phonemic paraphasias, paralexias, and paragraphias, and mild impairment of comprehension of complex oral and written sentences persisted. Subvocal and spatial acalculia, and secondary stage ideomotor apraxia had disappeared. Verbal IQ was 81 and performance IQ 89 (WISC-R ${ }^{13}$ ). Speech rehabilitation was continued at home for two years.

School attendance was resumed in 
Figure 1 T2 sequences on MRI. Parietal porencephalic cavity and perilesional hyperecho in the subcortical white matter, temporal cortex and external occipital cortex.
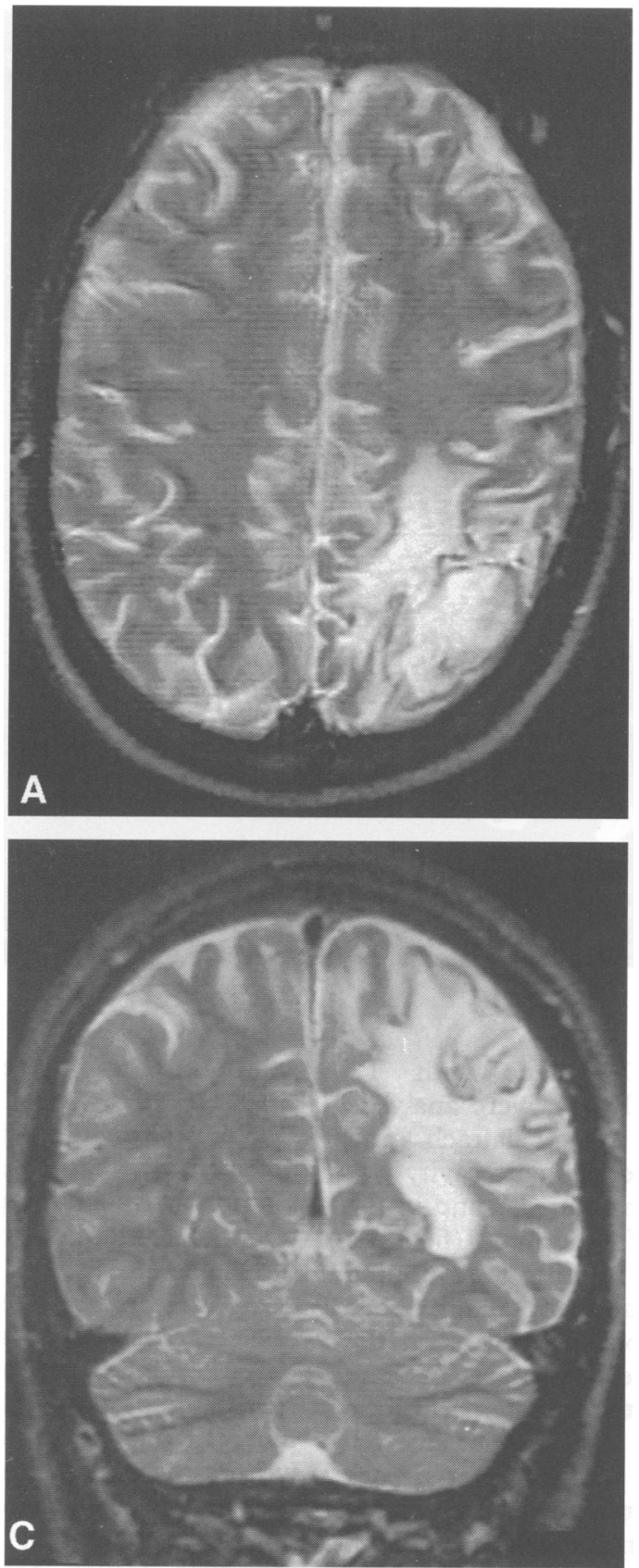

September 1989, with serious learning difficulties. When evaluated in February 1991, verbal IQ was 79 and performance IQ 107 (WAIS-R ${ }^{14}$ ). Learning was more deficient with verbal $\left(49 \cdot 5\right.$, battery 144 of Signoret ${ }^{15}$; normal $63.76(8.48)$ ) than visuospatial material (54.0; normal $64 \cdot 50(7 \cdot 16))$. In 1993 , the French version of the Boston diagnostic aphasia examination ${ }^{16}$ showed a mild understanding deficit for complex oral and written sentences and low performance on categorial evocation (animals: 10/min). The Wisconsin card sorting test $\mathrm{t}^{17}$ was normal.

Epileptic seizures occurred from November 1987, with a mean frequency of one every three months. They were stereotyped and perceived by the family members as a brief loss of contact for $\mathbf{3 0}$ to $\mathbf{4 0}$ seconds. The patient later described perception of objects (familiar or not) or of isolated words, written in black letters. These simple words

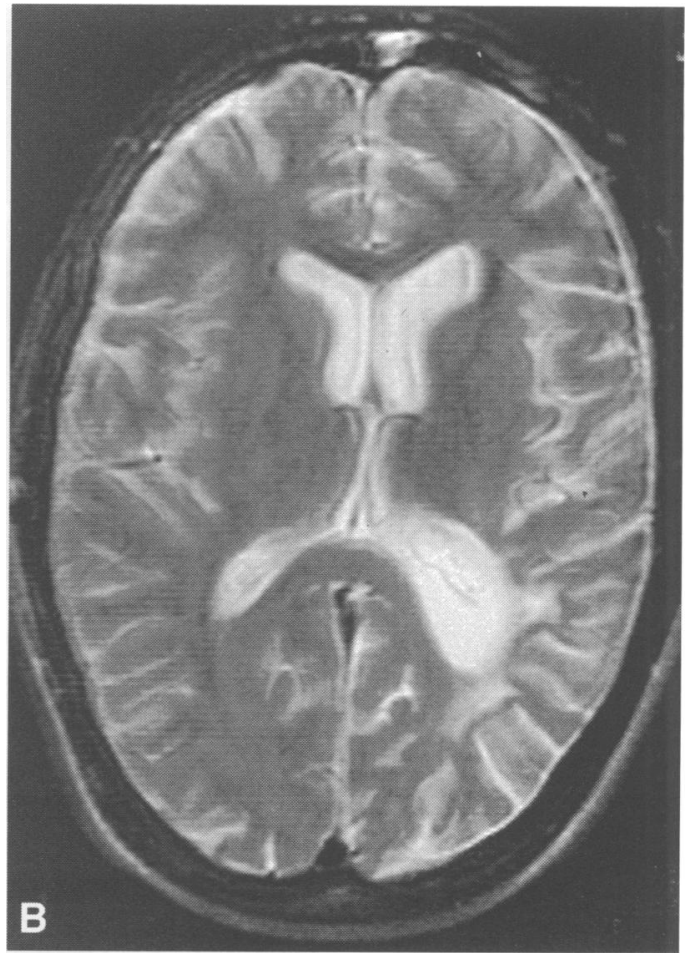

could refer to animals ("chameau": camel) or objects ("ciseaux": scissors; "magnetophone": tape recorder; "voiture": car); they had often been used during the few hours before seizure onset. He never perceived isolated letters or associated words. Aphasia was generally worse for one or two hours after the seizure. Electroencephalograms showed ample delta waves over the left anterior parietal and posterior temporal areas. On one of them a single spike and wave discharge spontaneously occurred, with phase opposition centred in the left inferior parietal lobe. Treatment with carbamazepine $(600 \mathrm{mg}$ per day) was started and the seizures disappeared.

Magnetic resonance imaging was performed in 1991, (Gyroscan (Philips)) with $6.5 \mathrm{~mm}$ thick scanner slices. Axial slices, per-

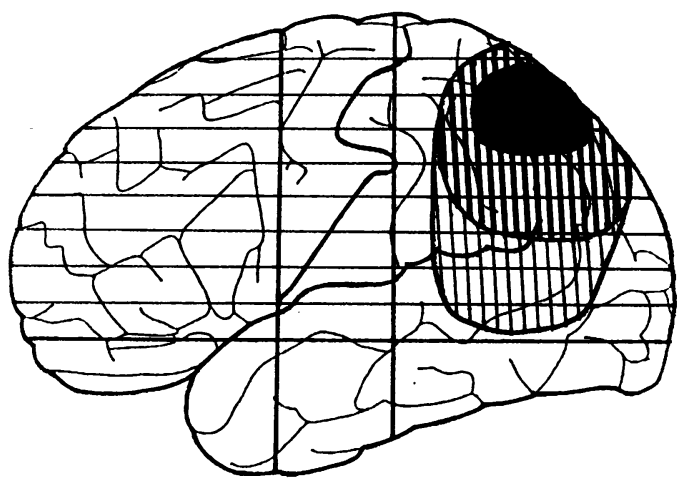

Figure 2 Three dimensional reconstruction of lesions with the Talairach and Tournoux atlas. There is $a$ porencephalic cavity in the superior part of the parietal lobe (dark area) and a perilesional hyperecho in the external temporal cortex and especially in the perilesional inferior parietal cortex (shaded areas). 
Figure 3 Single PET shows severe reduction in blood flow in the left parietal and temporal areas.

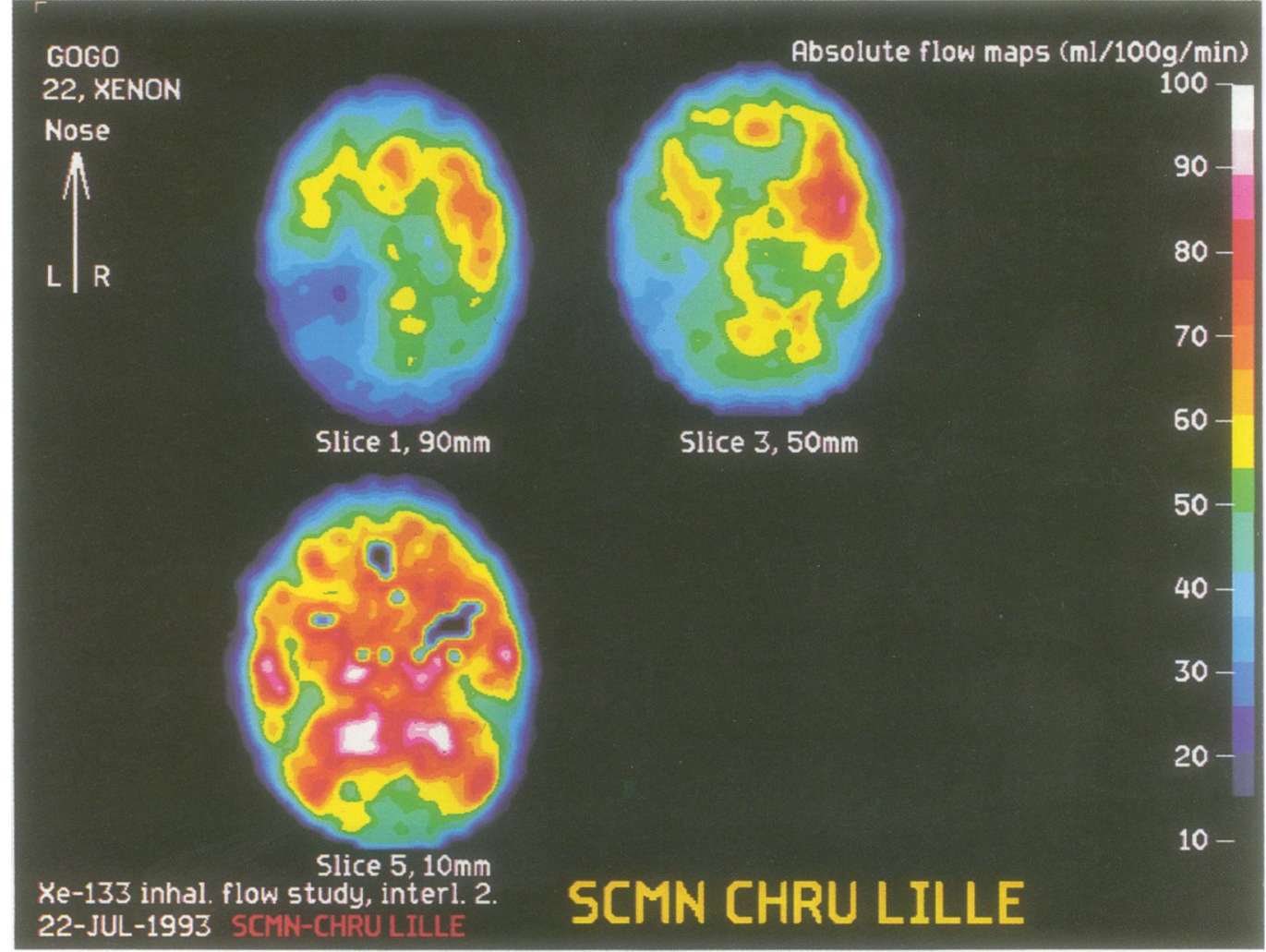

formed in the CA-CP plane with T2 sequences (TR 2700; TE 95), were analysed by comparison with the Talairach and Tournoux atlas. ${ }^{18} \mathrm{~A}$ porencephalic cavity was seen in the lower portion of area 7 and in the upper part of area 39 of Brodmann (fig 1); a hyperecho was noted in the surrounding cortical areas, over (5) and principally above $(39,40)$ the main lesion, as well as in the subcortical white matter; a more discrete hyperecho was noted in the middle part of the external temporal gyri and in the external occipital area. These lesions were later reconstructed on a lateral view of the brain (fig 2). Other lobes and the diencephalon were preserved. Cerebral blood flow was measured in 1993 with single photon emission CT and inhalation of xenon-133 (Tomomatic 564, Medimatic, Copenhagen). There was a severe reduction in blood flow in the superior parietal area as well as in the temporal area of the left hemisphere (fig 3).

\section{Discussion}

This patient presented, five months after traumatic haemorrhage of the left parietal area, with epileptic seizures associated with complex visual perceptions, one of the most noteworthy manifestations being hallucinations of written words.

At the secondary stage, deficits were close to those found in the temporoparietal syndrome ${ }^{19}$ - namely, Wernicke aphasia, acalculia, and ideomotor apraxia. Lesions defined by MRI more severely affected the parietal cortex. Cerebral blood flow was reduced in this area, and also in the adjacent middle external temporal and external occipital cortices.

We were unable to find any previous report of such a phenomenon in the literature. Complex visual hallucinations associated with temporal epileptic foci or with the temporal diffusion of seizures arising from occipital areas most often consist of scenes, faces, or objects. ${ }^{6}$ Illusion of familiarity and experiential phenomena would be associated with spreading of the epileptic activity from the temporal neocortex to the limbic area. ${ }^{820}$ If written messages, letters, and later words are analysed in the occipital and posterior temporo-occipital areas, ${ }^{10111921}$ it seems surprising that visual hallucinations with such materials have never been reported before. Word hallucinations in this patient could be sponding to the site of the cortical representation of the perceptive lexicon for written words. Such an orthographic lexicon has been suggested in cognitive psychology, and would be an essential element of the various models that have been proposed. ${ }^{22} 2324$ It has, furthermore, been suggested that it could be different for reading and spelling. ${ }^{23}$ In terms of structure-activity relations, it has been suggested by Dejerine ${ }^{11}$ that a centre for visual images of words is localised in the left angular gyrus (area 39 of Brodmann). This idea was widely accepted until recently, as most restricted lesions of this cortical area. ${ }^{1921}$ Recent work with PET and cognitive brain activation techniques in normal subjects have, however, brought arguments for localisation of the lexicon for written words in the medial extrastriate cortex ${ }^{25} 26$ or in the posterior part related to seizure discharge in an area correpatients with "alexia and agraphia" also had 
of the left middle temporal gyrus, ${ }^{27}$ and of the corresponding lexicon for spoken word recognition in the left superior and middle temporal gyri. ${ }^{27}$

The present case brings complementary arguments for a localisation in the inferior parietal or superior temporal cortex: this structure was indeed situated above the porencephalic lesion and ECG recording suggested that the epileptic focus was located in this cortical area. Closer relations between epileptic discharges and characteristics of the visual hallucinations are, however, questionable, as scalp recording did not allow a clear description of the diffusion of the seizures. A feeling of familiarity described by the patient furthermore suggested diffusion toward limbic areas. ${ }^{820}$

The facilitating part of the procedure used in language therapy merits discussion. During the first months after head trauma, the facilitation of spoken and written lexical production by previous internal evocation of the written form of the word suggested that this patient had a relatively preserved access to the lexicon for written words (orthographic lexicon)..$^{23}$ Such a mental operation was theoretically possible if the associated cortical structures were intact, justified by the fact that the main lesions were in the superior parietal area. The onset of the particular characteristics of the epileptic manifestations that the patient reported seem to have been favoured by his recent experiences. One hypothesis could be that rehabilitation had promoted functional "hyperactivity" in these lexicon representations or have facilitated their accessibility.

1 Penfield W, Jasper H. Epilepsy and the functional anatomy of the human brain. Boston, MA: Little Brown Co, 1954.

2 Russel WR, Whitty CWM. Studies in traumatic epilepsy: 3. Visual fits. F Neurol Neurosurg Psychiatry 1955;18: 79-96.

3 Bancaud J. Les crises épileptiques d'origine occipitale (étude stéréo-électroencéphalographique). Revue d'Otoneuro-ophtalmologia 1969;41:299-315.

4 Ludwig BI, Atmone Marsan C. Clinical ictal patterns in epileptic patients with EEG temporal lobe foci. Neurology 1975;25:463-71.

5 Salanova V, Andermann F, Olivier A, Rasmussen T Quesney LF. Occipital lobe epilepsy: electroclinica manifestations, electrocorticography, cortical stimulation and outcome in 42 patients treated between 1930 and 1991. Surgery of occipital lobe epilepsy. Brain 1992;115:1655-80.

6 Takeda A, Bancaud J, Talairach J, Bonis A, Bordas-ferrer M. Concerning epileptic attacks of occipital origin. M. Concerning epileptic attacks of occipital origi

7 Williamson PD, Boon PA, Spencer DD, Spencer SS, Mattson RH. Occipital and parietal epilepsy. Epilepsia 1988;29:682.

8 Gloor P, Olivier A, Quesney LF, Bergsma P. The role of the limbic system in experimental phenomena of temporal lobe epilepsy. Ann Neurol 1982;12:129-44.

9 Mesulam MM. Patterns in behavioural neuroanatomy: association areas, the limbic system, and hemispheric specialization. In: Mesulam MM, ed. Principles of behav ioral neurology. Philadelphia: Davis Co. 1985:1-70.

10 Dejerine J. Contribution à l'étude anatomo-pathologique et clinique des différentes variétés de cécité verbale. Mémoirec de la Société de Biologie 1892;4:61-90.

11 Dejerine J. Sur un cas de cécité verbale avec agraphie, suivi d’autopsie. Mémoires de la Société de Biologie suivi d'autopsie.

12 Oldfield RC. The assessment and analysis of handedness: the Edinburgh inventory. Neuropsychologia 1971;9: 97-113.

13 Wechsler D. Echelle d'intelligence de Wechsler pour enfantsrévisée. Paris: Les éditions du Centre de Psychologie Appliquée. 1982.

14 Wechsler D. Echelle d'intelligence de Wechsler pour adultesrévisée. Paris: Les éditions du Centre de Psychologie Appliquée. 1989.

15 Signoret JL. Batterie d'éfficience mnésique. BEM 144. Paris: Elsevier, 1991.

16 Mazaux JM, Orgogozo JM. Echelle d'évaluation de l'aphasie. Issy-les-Moulinaux: Editions Scientifiques et Psychologiques. 1982.

17 Nelson HE. A modified card sorting test sensitive to frontal lobe defects. Cortex 1976;12:313-24

18 Talairach J, Tournoux P. Co-planar stereotaxic atlas of the human brain. Stuttgart: Georg Thieme Verlag, 1988.

19 Botez MI, Botez T, Olivier M. Parietal lobe syndromes. In: Vinken PJ, Bruyn GW, Klawans HL, eds. Handbook In: Vinken PJ, Bruyn GW, Klawans HL, eds. Handbook of clinical neurology. Vol 45.

20 Gloor P. Experiential phenomena of temporal lobe epilepsy. Facts and hypotheses. Brain 1990;113 1673-94

21 Geschwind N. Disconnexion syndromes in animals and man. Part I. Brain 1965;88:237-94.

22 Warrington EK, Shallice T. Word-form dyslexia. Brain 1980;103:99-112.

23 Patterson KE, Kay J. Letter-by-letter reading: psychological description of a neurological syndrome. $Q \mathcal{F}$ Exp Psychol 1982;34A:41 1-41.

24 Friedman RB, Hadley JA. Letter-by-letter surface alexia. Cognitive Neuropsychology 1992;9:185-208.

25 Petersen SE, Fox PT, Posner MI, Mintun M, Raichle ME. Positron emission tomographic studies of the cortical anatomy of single-word processing. Nature 1988; cal anatom

26 Petersen SE, Fox PT, Snyder AZ, Raichle ME. Activation of extrastriate and frontal cortical areas by visual words and word-like stimuli. Science 1990;249:1041-4.

27 Howard D, Patterson K, Wise R, Brown D, Firston K Weiller C, Frackowiak R. The cortical localization of the lexicons. Brain 1992;115:1769-82. 